02

\title{
Управление сверхпроводящими переходами нанопроводов с использованием затворов без гальванической связи для создания электронных устройств на основе сверхпроводников
}

\author{
(C) Б.А. Гурович ${ }^{1}$, К.Е. Приходько ${ }^{1,2, \text { ॠ , Л.В. Кутузов }}{ }^{1}$, Б.В. Гончаров ${ }^{1}$ \\ ${ }^{1}$ Национальный исследовательский центр „Курчатовский институт“ \\ Москва, Россия \\ ${ }^{2}$ Национальный исследовательский ядерный университет „МИФИ“, \\ Москва, Россия \\ ๑E-mail: prihodko_ke@nrcki.ru
}

Поступила в Редакцию 26 марта 2020 г.

В окончательной редакции 26 марта 2020 г.

Принята к публикации 2 апреля 2020 г.

\begin{abstract}
Показана возможность переключения нанопровода из $\mathrm{NbN}$ из сверхпроводящего состояния в нормальное бесконтактным способом за счет пропускания тока через затвор, который расположен на определенном расстоянии от нанопровода. Затвор отделен от нанопровода слоем $\mathrm{Al}_{2} \mathrm{O}_{3}$, содержит интегрированное сопротивление, созданное под действием ионного облучения. Экспериментально получены зависимости минимальной мощности, выделяемой на затворе, достаточной для перевода нанопровода в нормальное состояние, в зависимости от величины постоянного тока через нанопровод. На основе данного принципа создан инвертор сигнала, содержащий три последовательных каскада, что показывает потенциальную возможность применения метода для формирования элементной логической базы криогенного компьютера.
\end{abstract}

Ключевые слова: тонкие сверхпроводящие пленки $\mathrm{NbN}$, бесконтактное переключение состояния сверхпроводника, крио-электронные устройства, интегрированные криогенные резисторы.

DOI: $10.21883 /$ FTT.2020.09.49764.23H

\section{1. Введение}

В настоящее время актуальной является задача поиска систем, которые могли бы заменить вычислительные устройства на основе полупроводниковых структур в связи с значительным энергопотреблением последних, что становится критичным в связи с созданием суперкомпьютеров, объединяющих большое число одновременно работающих процессоров. Кроме существенного энергопотребления [1], кремниевые процессоры также характеризуются ограничениями по тактовой частоте, что обусловлено достижением предельной величины подвижности носителей в канале транзисторов, определяемой физическими характеристиками материала [2].

Применение сверхпроводников для создания вычислительных устройств представляется весьма перспективным не только в связи с существенным уменьшением энергопотребления, но и в связи с потенциально большими достижимыми частотами переключения. В настоящее время в мире ведется поиск различных вариантов создания логических устройств на основе сверхпроводников. Развивается направление создания логических устройств с использованием квантов магнитного потока и джозефсоновских переходов (RSFQ) [3,4], а также продемонстрирована логика, работающая на сверхпроводящих аналогах транзисторов $\left(, n\right.$,ron $\left.^{66}\right)[5]$.
Логические схемы, основанные на магнитных потоках и использовании джозефсоновских переходов (RSFQ), активно применяется в настоящее время для проектирования криогенных компьютеров, в связи с характерными малыми временами переключения ( 1 ps) и энергиями, требуемыми для единичного переключения $\left(<10^{-19} \mathrm{~J}\right)$ [1]. Продемонстрирована работа криогенных вычислительных схем RSFQ на частоте $770 \mathrm{GHz}[6]$.

На сегодняшний день для создания суперкомпьютеров используются полупроводниковые процессоры, для которых характерно значительное выделение энергии [1], что сдерживает их развитие и представляет существенную проблему при эксплуатации. Характерное значение интегрального энерговыделения отдельного транзистора в современном полупроводниковом процессоре можно оценить путем анализа средней электрической мощности, потребляемой процессором. Так, например, согласно спецификации, процессор „POWER9“ фирмы IBM, изготовленный по проектным нормам $14 \mathrm{~nm}$ и технологии кремний на изоляторе (SOI), выделяет при работе электрическую мощность $W_{0}=190 \mathrm{~W}$ при общем числе транзисторов $N=8 \cdot 10^{9}$ [7]. Поскольку одновременно все транзисторы никогда не работают (среднее число одновременно работающих транзисторов составляет $\sim 50 \%$ ), оценка средней мощности, приходящейся на один транзистор, дает $W_{s}=2 \cdot W_{0} / N \sim 47.5 \mathrm{nW}$. В эту мощность включается вся дополнительная мощность, 
выделяемая в системе соединительных проводов (металлизации) и пр.

В настоящей работе продемонстрирована возможность использования эффекта контролируемого переключения сверхпроводящего нанопровода из сверхпроводящего состояния в нормальное и обратно за счет управляющего сигнала по затвору, расположенному на некотором расстоянии от нанопровода и не имеющего с ним гальванической связи [8]. В работе также показана возможность создания элемента логических устройств на основе данного вида переключений.

В работе в качестве низкотемпературного сверхпроводника выбран поликристаллический нитрид ниобия $\mathrm{NbN}$ с типом кристаллической решетки $\mathrm{B} 1(\mathrm{NaCl})$, обладающий сверхпроводящими свойствами и самой высокой критической температурой сверхпроводящего перехода $T_{c} \approx(12 \ldots 14) \mathrm{K}$, в случае ультратонких пленок, среди других сверхпроводников типа В1, что делает его перспективным для создания функциональной элементной базы криоэлектроники.

В настоящее время в мире на основе сверхпроводящих нанопроводов из $\mathrm{NbN}$ создаются активные элементы наноразмерных масштабов: сверхпроводящие однофотонные детекторы и счетчики единичных фотонов (SSPD) [9,10], болометры на горячих электронах (HEB) $[11,12]$.

В сверхпроводящие нанопровода из $\mathrm{NbN}$ различными методами встраиваются пассивные элементы: резисторы, конденсаторы, а также элементы индуктивности из других материалов, например, с применением технологии „lift-off“, что при массовом производстве (в отличие от изготовления лабораторных образцов) сопряжено с большими трудностями и затратами. В результате создаются приборы, работа которых основана на эффекте Джозефсона, например, сверхпроводящий квантовый интерферометр (SQUID) [13]. Для широкого внедрения таких устройств существует необходимость разработки технологии их изготовления, обеспечивающей высокое качество таких приборов и низкую себестоимость, что с учетом сказанного представляется достаточно проблематичным.

Разработанный в НИЦ „Курчатовский институт“ комплекс радиационных методов управляемой модификации химического состава и свойств тонкопленочных материалов в процессе облучения низкоэнергетическими ионными пучками $[14,15]$, в частности $\mathrm{NbN}$ [16], позволяет создавать для криоэлектронных устройств композитные материалы и различные функциональные элементы (например, сопротивления) из одного исходного материала.

Основа методов радиационно-индуцированной трансформации свойств веществ, например, при создании материала, проявляющего металлические свойства при криогенных температурах, заключается в модификации атомного состава тонкопленочного сверхпроводника за счет воздействия на выбранные участки вещества потоками ускоренных частиц смешанного состава: ионов водорода, с энергией, достаточной для создания радиационных повреждений в исходном веществе, и ионов, которые требуется ввести в состав формируемого химического соединения - так называемый метод селективного замещения атомов (С3А) [15]. В результате такого облучения инициируется процесс замены атомов исходного химического соединения на новые атомы, содержащиеся в ионном пучке, в данном случае, замена атомов азота в нитриде ниобия на атомы кислорода [17].

Как известно, переход тонкого сверхпроводящего нанопровода из сверхпроводящего состояния в нормальное происходит из-за превышения значения критического тока (тока распаривания куперовских пар) [18] и последующим образованием и ростом „горячих областей“ (hot spots), содержащих нормальную фазу [19].

Также возможно формирование центров проскальзывания фазы (ЦПФ) в сверхпроводящем нанопроводе до его перехода в нормальное состояние [20], что вызывает возникновение на нем разности потенциалов, которая должна учитываться при проектировании криогенных электрических схем. Такие переходы наблюдаются как для узких и тонких сверхпроводников с сечением от $10^{-2}$ до $1 \mu \mathrm{m}^{2}[21]$, так и для широких тонкопленочных сверхпроводников.

В работе [22], при изучении перехода сверхпроводящего нанопровода из $\mathrm{NbTiN}$ в нормальное состояние путем подачи импульсов тока было показано, что при температурах, существенно ниже $T_{c}$, преобладает механизм разрушения сверхпроводимости по типу образования и роста „горячих областей“. Этот механизм характеризуется малыми временами отклика, что делает его применение перспективным в области сверхвысоких частот.

Созданные устройства на основе эффекта разрушения сверхпроводимости в узком месте канала за счет превышения критического тока по механизму образования и роста „горячей области“ (hot spot) [5] были успешно использованы для демонстрации возможности создания основных логических элементов, как основы будущих криогенных процессоров.

В настоящей работе исследована возможность переключения сверхпроводящего нанопровода из $\mathrm{NbN}$ в нормальное состояние бесконтактным способом. Управление осуществляется путем пропускания тока через параллельный нанопровод, находящегося на определенном расстоянии от него.

\section{2. Эксперимент}

На рис. 1 показано изображение образца, полученное в растровом электронном микроскопе для случая планарной геометрии, когда нанопровод $(1-2)$ параллелен затвору (3-4) или (5-6) с интегрированными сопротивлениями $R g$ и находится на некотором расстоянии от затвора, в данном случае, $350 \mathrm{~nm}$. 


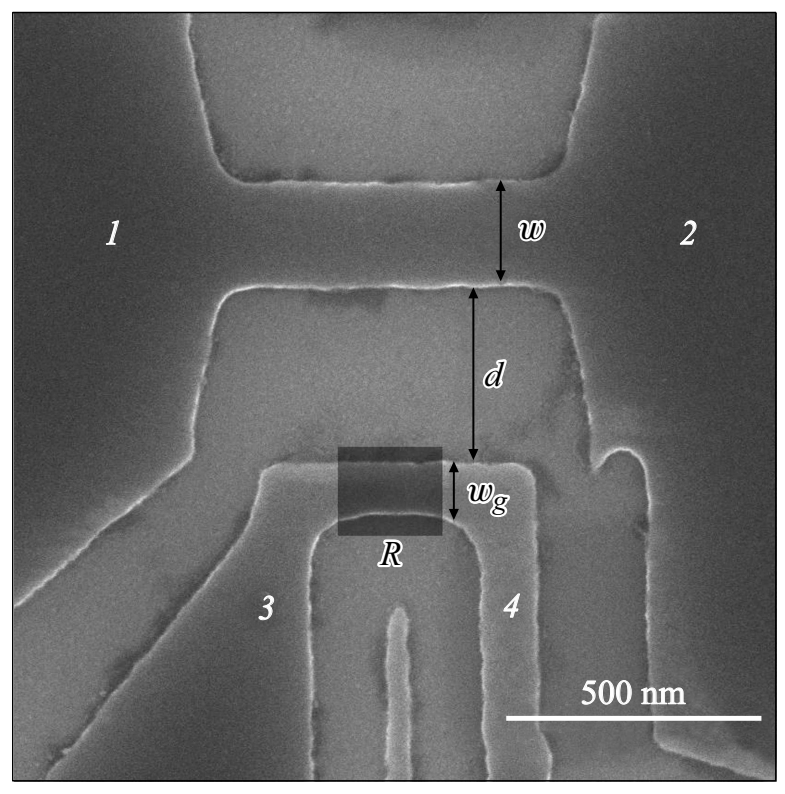

Рис. 1. Экспериментальный образец: (1)-(2) - нанопроводник из $\mathrm{NbN},(3)-(4)-$ затвор из $\mathrm{NbN}$ с интегрированным сопротивлением $(R)$, созданным под действием ионного облучения.

Изготовление образца проводилось следующем образом. На подложку из монокристаллического кремния, покрытого слоем термического оксида кремния толщиной $1.2 \mu \mathrm{m}$, или на подложку из монокристаллического сапфира методом катодного распыления мишени из ниобия в атмосфере азота при температуре подложки $750-850^{\circ} \mathrm{C}$ наносилась пленка нитрида ниобия толщиной $5 \mathrm{~nm}$. Нанесение пленки происходило аналогично тому, как это делалось в работе [23]. Для данных пленок характерная критическая температура составляет $\sim(12-14)$ К. Часть образцов изготавливалась при температуре подложки $\sim(20-50)^{\circ} \mathrm{C}$. Для данных пленок критическая температура $T_{c}$ составляла $\sim(8-9) \mathrm{K}$.

После нанесения сплошной пленки из нитрида ниобия, методами взрывной фотолитографии на поверхности формировались металлические контакты из двухслойной металлической пленки $\mathrm{Ni} / \mathrm{Pt}$.

После нанесения металлических контактов производилось структурирование пленки для формирования нанопроводника шириной $w(1)-(2)$ (см. рис. 1) и управляющего затвора шириной $w_{g}$ в виде узкого электрода (3)-(4), отделенного от нанопроводника зазором различной ширины $d$ от 100 до $350 \mathrm{~nm}$. При этом, длина рабочей части затвора (3)-(4), обращенной к нанопроводнику, составляла $\sim 500 \mathrm{~nm}$. Структурирование пленки выполнялось стандартными методами электронной литографии на электронном микроскопе „Helios Nanolab 650" (FEI), оснащенном литографической приставкой (Raith) и последующего плазмо-химического травления.
После изготовления нанопроводников, в затворе формировалось интегрированное сопротивление $R$ путем облучения части затвора через маску смешанным ионным пучком для преобразования сверхпроводящего материала в фазу, проявляющую металлические свойства при температуре $4.2 \mathrm{~K}$ [24]. Интегрированное сопротивление формировалось в участке затвора, расположенном непосредственно напротив нанопровода для минимизации расстояния между резистивным участком затвора и нанопроводом.

Изготовленные структуры нанопроводов и затвора с интегрированным сопротивлением сверху покрывались слоем аморфного оксида алюминия $\mathrm{Al}_{2} \mathrm{O}_{3}$ толщиной $(10-20) \mathrm{nm}$ при температуре подложки $20^{\circ} \mathrm{C}$ методом катодного распыления.

Вышеописанная процедура изготовления образцов относится к структурам планарного типа, в которых нанопровод и затвор с интегрированным сопротивлением находятся в одном слое. Такой способ создания планарных структур не позволяет сформировать зазор между нанопроводом и затвором менее $\sim 100 \mathrm{~nm}$, в связи с ограничениями, обусловленными радиационной стойкостью использованного материала маски (ПММА).

Для уменьшения расстояния между затвором и нанопроводом были созданы двухслойные структуры, в которых нанопровод и затвор с интегрированным сопротивлением располагались в двух разных слоях, разделенных слоем аморфного диэлектрика - оксида алюминия толщиной $10-35 \mathrm{~nm}$, нанесенного методом катодного распыления.

Для проведения измерений электрофизических свойств сверхпроводящего провода при различных токах затвора, к платиновым контактам на образце прижимными лапками подсоединялся источник тока (контакт 1), земляной кабель (контакт 2) а также источник тока затвора (контакт 3 или 5, в зависимости от используемого затвора). В экспериментах использовался только один затвор: либо первый, либо второй. Контакты 4 и 6 также были подсоединены к земле.

Стабилизированные источники тока были реализованы с использованием двух каналов измерительной установки „Keithley 4200-CS“, которые одновременно с подачей тока через нанопровод и тока на затвор, производили измерения напряжений, соответственно, на нанопроводе и затворе. Таким способом определялись вольт-амперные характеристики. Схема электрических измерений являлась двухконтактной, поэтому в результаты измерений всегда входили контактные сопротивления и сопротивления подводящих кабелей, которые суммарно составляли величину (1.5-3) $\Omega$. Оценка контактных сопротивлений и сопротивлений коммутирующих кабелей производилась по наклону вольт-амперной характеристики в условиях, когда нанопровод из $\mathrm{NbN}$ находился в сверхпроводящем состоянии. Все электрические измерения выполнялись при температуре $4.2 \mathrm{~K}$, которая обеспечивалась термостатированием образца в жидком гелии. 
Для минимизации влияния внешних помех на сверхпроводящие переходы в нанопроводах, измерения вольтамперных характеристик выполнялись с включением пассивного высокочастотного фильтра „Bias Теe“ последовательно с источником тока на входе в измерительном тракте. Для каждой точки по напряжению на затворе снимались последовательно не менее пяти вольт-амперных зависимостей на различных однотипных образцах.

\section{3. Результаты и обсуждение}

Вольт-амперные характеристики затвора, шириной $w_{g}=100 \mathrm{~nm}$, с интегрированным сопротивлением и собственная вольт-амперная характеристика нанопровода, шириной $w=200 \mathrm{~nm}$, находящегося от затвора на расстоянии $d=350 \mathrm{~nm}$ (см. рис. 1), снятые независимо друг от друга (при отсутствии сигнала на соседнем элементе), показаны на рис. 2. Как видно из рис. 2, до перехода необлученной части затвора в нормальное состояние при токе $I_{1} \sim 8.5 \mu \mathrm{A}$, сопротивление затвора постоянно и равно $\sim 5.8 \mathrm{k} \Omega$. Нанопровод (вольт-амперная характеристика которого снималась при нулевом токе затвора) переходит в нормальное состояние при токе $\sim 96 \mu \mathrm{A}$, а возвращается в сверхпроводящее состояние из нормального при токе $\sim 16.5 \mu \mathrm{A}$ (см. рис. 2 ).

Наличие резистивного элемента в затворе позволило точно измерить значение минимальной мощности, необходимой для перехода нанопровода в нормальное состояние, поскольку, по мере увеличения тока через затвор, содержащий резистивный элемент, мощность также плавно увеличивалась, в отличие от предыдущего случая, когда выделение мощности происходило скачком, только после перехода затвора в нормальное состояние. Фиксация факта перехода нанопровода в

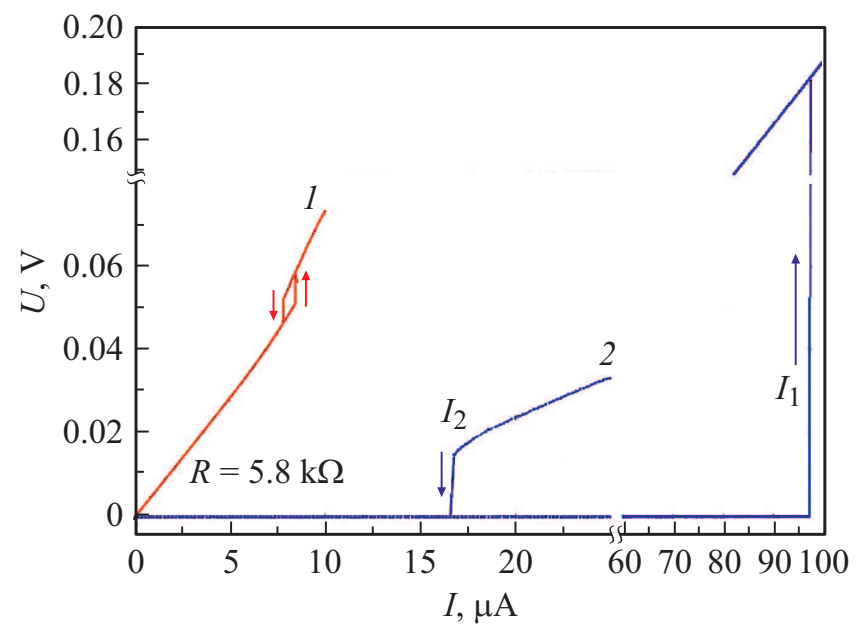

Рис. 2. Вольт-амперные характеристики: (1) - затвора $\left(w_{g}=100 \mathrm{~nm}\right) \quad$ с интегрированным сопротивлением $R=5.8 \mathrm{k} \Omega$; $(2)-$ нанопровода $(w=200 \mathrm{~nm})$ при нулевом токе через затвор.

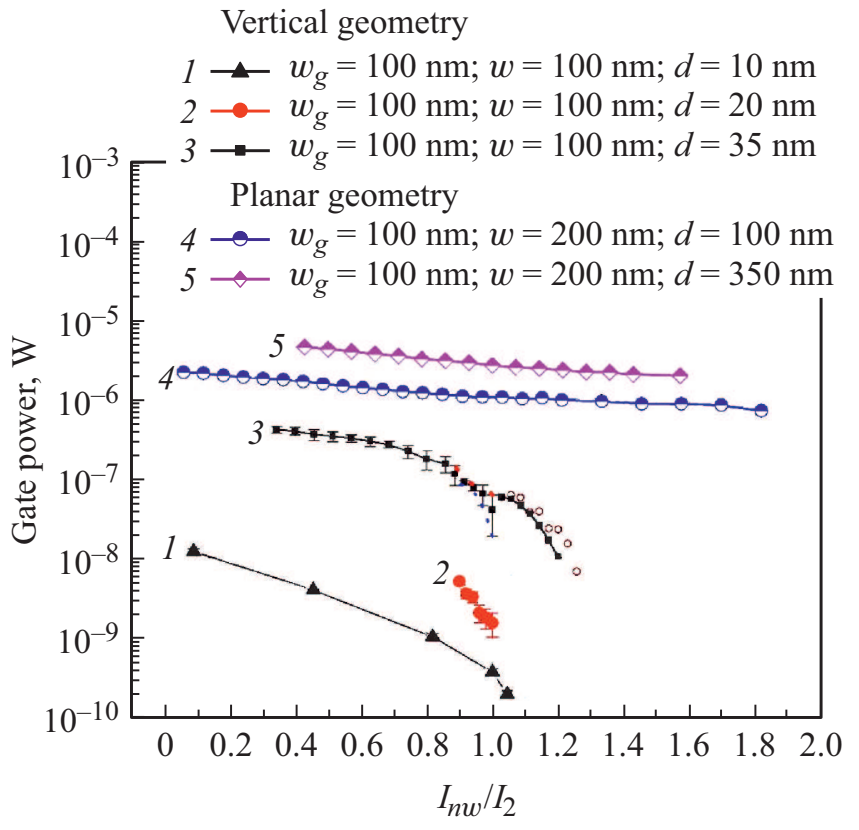

Рис. 3. Зависимость минимальной мощности, выделяемой в затворе, для перевода нанопровода в нормальное состояние, от нормированного тока через нанопровод (нормировка производится на величину тока $I_{2}$ обратного $N \rightarrow S$ перехода нанопровода) в вертикальной (ВГ) и планарной (ПГ) геометрии расположения затвора и нанопровода.

нормальное состояние осуществлялось по скачку напряжения на нанопроводе.

На рис. 3 представлены зависимости минимальной мощности, выделяемой в затворе, достаточной для перевода нанопровода в нормальное состояние, в зависимости от величины постоянного тока, пропускаемого через нанопровод. Поскольку ток обратного перехода нанопровода из нормального в сверхпроводящее проявляет большую стабильность, чем ток прямого перехода из сверхпроводящего состояния в нормальное, постоянное значение тока через нанопровод на рисунке 3 нормировалось именно на величину тока обратного перехода нанопровода.

Как видно из рис. 3, по мере увеличения тока через нанопровод, величина минимальной мощности, выделяемой на затворе, необходимой для перевода нанопровода в нормальное состояние, уменьшается. В то же время, увеличение величины зазора между затвором и нанопроводом, вызывает увеличение требуемой для перехода мощности. Использование покрытия из оксида алюминия позволяет реализовать многослоевую схему, используя его в качестве межслоевого изолятора.

Полученные в настоящей работе минимальные значения мощности, выделяемой на затворе, необходимые для переключения нанопровода из сверхпроводящего состояния в нормальное составили $\sim 0.36 \mathrm{nW}$ при расстоянии между затвором и нанопроводом $10 \mathrm{~nm}$. Поскольку на самом нанопроводе выделяется половина 
мощности, выделяемой на затворе (в нем два одинаковых сопротивления), то суммарно на единичный каскад выделяется $\sim 0.54 \mathrm{nW}$. Данное значение минимальной мощности, выделяемой на единичном элементе, примерно в 88 раз меньше, чем мощность, выделяемая на единичном полупроводниковом транзисторе. Однако, с учетом того, что для отведения тепла при $4 \mathrm{~K}$ в современной машине замкнутого цикла требуется примерно в 500 раз большая тепловая мощность [25], итоговая величина мощности потребления единичным каскадом, полученная на настоящий момент, составляет $\sim 270 \mathrm{nW}$. Поскольку для отведения тепла от полупроводникового транзистора требуется дополнительная мощность в полтора раза большая, чем он потребляет [25], суммарная мощность, приходящаяся на полупроводниковый транзистор, составляет $2.5 \cdot W_{s}=119 \mathrm{nW}$. Таким образом, минимальная мощность потребления, полученного на настоящий момент единичного каскада инвертора, с учетом теплоотвода, в 2.3 раза больше, чем приходится на современный полупроводниковый транзистор.

Дальнейшее снижение мощности возможно при уменьшении размеров переключаемого сегмента нанопровода, уменьшении расстояния между затвором и нанопроводом, а также за счет снижения тока $I_{2}$ в переключаемом нанопроводе.

Быстродействие работы системы требует проведения экспериментов по определению предельных частот переключения предложенным методом, которые проводятся в настоящее время.

Полученные в работе данные свидетельствуют о том, что причиной перехода нанопровода в нормальное состояние является его локальный нагрев, обусловленный выделением тепла в затворе при достижении определенной мощности тепловыделения в затворе, изначально содержащем резистивный элемент. Переход нанопровода в нормальное состояние имеет место при определенном минимальном значении мощности тепловыделения в затворе $\left(W_{\min }\right)$. Значение $W_{\min }$ уменьшается с ростом величины постоянного тока, протекающего через нанопровод, что обусловлено, по-видимому, уменьшением величины плотности критического тока сверхпроводника с ростом его температуры. Уменьшение расстояния между выделяющим тепло затвором и нанопроводом также снижает величину минимальной мощности тепловыделения $\left(W_{\min }\right)$, необходимой для перехода нанопровода в нормальное состояние.

Указанные экспериментальные факты свидетельствуют о том, что ключевым процессом, определяющим возможность управления величиной критического тока нанопровода путем пропускания тока через находящийся в нормальном состоянии затвор без гальванической связи между ними, является передача тепла от затвора к нанопроводу и, соответственно, инициированный этим теплом нагрев нанопровода. Процесс передачи тепла зависит от теплопроводности среды, разделяющей нанопровод и затвор, расстояния между ними и условиями теплоотвода термостата. Также важным является увеличение температуры нанопровода в результате поступления тепла от затвора, зависящее от геометрических размеров нанопровода и условий его теплоотвода и зависимость плотности критического тока нанопровода от его температуры.

Установлено, что напыление дополнительного диэлектрического слоя на указанные наноустройства приводит к значительному снижению мощности, требуемой для управления переключением нанопровода. Кроме того, показано, что при создании многослойных устройств такого типа, не требующих вертикальных межсоединений, можно подобрать разумную минимальную достаточную толщину разделительного диэлектрика, обеспечивающего отсутствие взаимного негативного влияния соседних слоев, содержащих активные наноустройства.

Существенным обстоятельством, следующим из полученных результатов, является очевидная возможность использования обнаруженного эффекта для управления состоянием сверхпроводящих нанопроводов путем пропускания тока через затвор, находящийся на наноразмерном расстоянии, без гальванической связи между ними для создания различных логических схем и усилителей в нанокриоэлектронных устройствах.

По результатам исследований экспериментально продемонстрирована возможность создания многокаскадных логических схем без гальванической связи на основе сверхпроводящих нанопроводов.

На рис. 4, $a$ показан созданный многокаскадный инвертор сигнала, сформированный в плоской геометрии, а на рис. $4, b$ - его эквивалентная электрическая схема. Контакты 2, 3, 4 подключаются к источнику постоянного напряжения и в соответствующих сверхпроводящих нанопроводах сформированы интегрированные сопротивления $R_{2}, R_{3}$ и $R_{4}$. Сопротивления $R_{2}, R_{3}$ и $R_{4}$ подбираются таким образом, чтобы выполнялись три условия:

(I) Опорное напряжение создает в сверхпроводящих проводах ток $I_{0}$, меньше критического для узких участков нанопровода;

(II) Ток $I_{0}$, протекающий, например, через $R_{2}$, выделяет достаточную мощность, чтобы инициировать переход в нормальное состояние узкого участка соседнего нанопровода, находящегося на небольшом расстоянии, в данном случае, узкого участка в нанопроводе 3 . Переход узкого участка нанопровода 3 в нормальное состояние вызывает увеличение общего сопротивления нанопровода, что, с учетом постоянного напряжения на нем, вызывает уменышение тока через нанопровод до значения $I$;

(III) Третьим условием подбора величины сопротивления узкого участка нанопровода в нормальном состоянии является: ток $I$ через сопротивление $R_{3}$ недостаточен для прогрева соседнего узкого участка нанопровода 4 и, соответственно, для его перехода в нормальное состояние. 

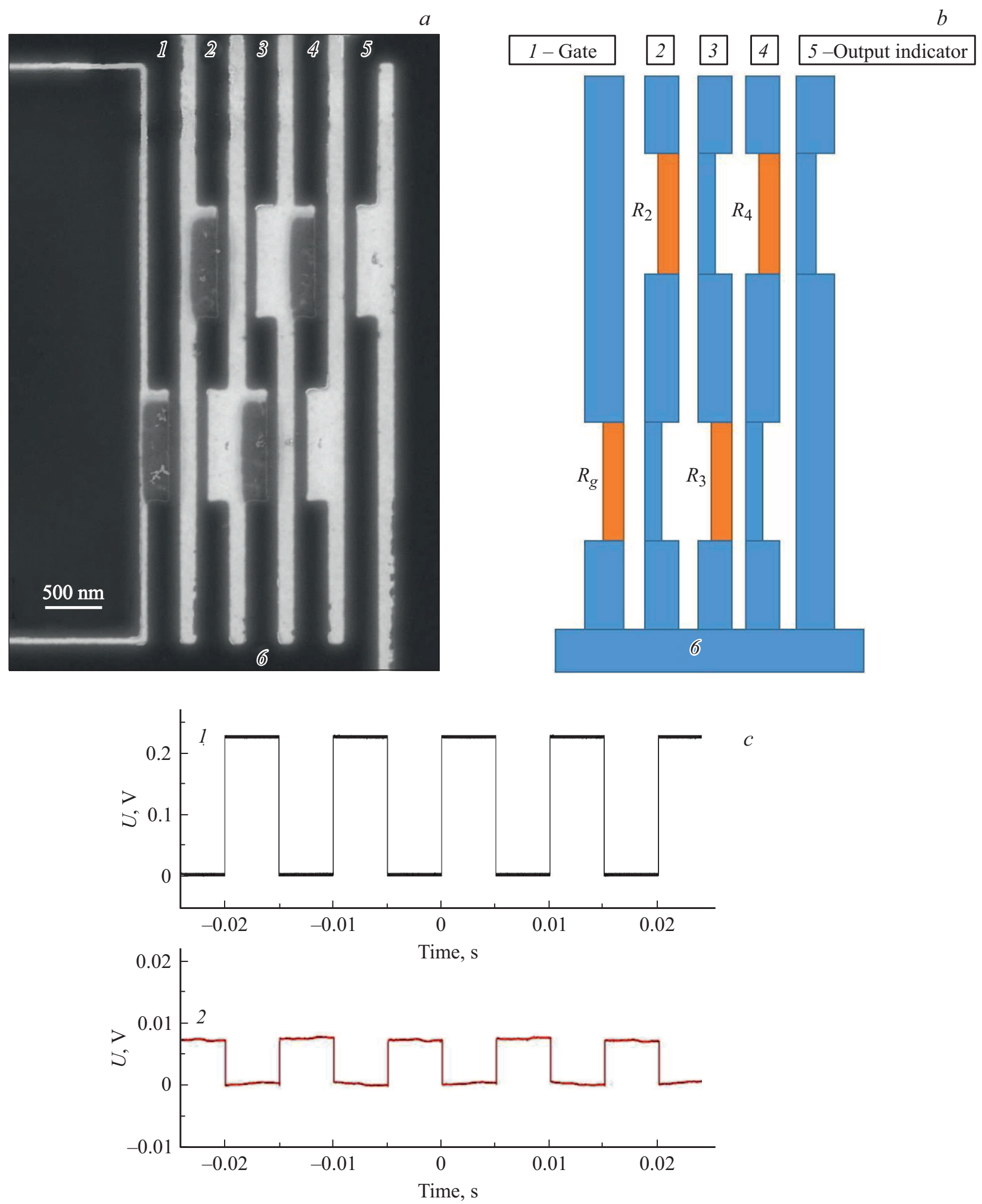

Рис. 4. Многокаскадный инвертор без гальванической связи: $(a)$ - изображение структуры; $(b)-$ электрическая схема; $(c)$ осциллограмма работы инвертора: (1) - сигнал на затворе; (2) - инвертированный сигнал на выходе.

Принцип работы инвертора основан на выполнении условий (I), (II) и (III). Пусть входной сигнал отсутствует, ток через $R_{g}$ равен нулю и затвор не греется. Тогда по нанопроводу 2 течет ток $I_{0}$, и в нанопроводе 2 узкий участок остается в сверхпроводящем состоянии. В нанопроводе 3 узкий участок переходит в нормальное состояние и через него течет ток $I$. В нанопроводе 4 узкий участок находится в сверхпроводящем состоянии 
и так далее. Таким образом, нанопровода чередуются по состоянию узких участков. После возникновения сигнала на затворе, он прогревает соседний узкий участок нанопровода 2, ток в нем падает до значения $I$, и следующий нанопровод 3 переходит в состояние с током $I_{0}$, а следующий нанопровод $4-$ в состояние с током I и так далее. Происходит изменение состояния в каждом нанопроводе.

Осциллограммы работы инвертора представлены на рис. 4,c. Видно, что при отсутствии входного сигнала на затворе (кривая 1 на рис. 4,c) на выходе наблюдается высокий уровень напряжения (кривая 2 на рис. 4,c), а при подаче сигнала на затвор, на выходе наблюдается низкий уровень сигнала. Данные на рис. 4, $c$ получены на низкой частоте и для изучения предельных достижимых частот переключения бесконтактного инвертора в настоящее время проводятся соответствующие высокочастотные измерения.

Созданный в настоящей работе инвертор содержит три последовательных каскада для демонстрации возможности реализации такого способа формирования логических элементов с последовательным бесконтактным методом передачи информации. Простейший инвертор с единичным каскадом содержит только затвор, второй нанопровод и выход-индикатор.

Полученные в работе результаты открывают перспективу создания устройств, содержащих многослойные логические элементы на базе нанокристаллических сверхпроводящих нанопроводов, при этом затворы и управляемые нанопровода могут быть расположены в различных слоях, разделенные слоем тонкого диэ̆лектрика.

\section{4. Выводы}

В работе описан метод, который был использован для создания бесконтактных переключателей на основе нанопроводов из сверхпроводящего $\mathrm{NbN}$, работающих на принципе управления критическим током нанопровода за счет тепла, выделяемого на находящемся рядом затворе без гальванической связи между ними, что позволяет избежать необходимости электрического согласования различных элементов (каскадов) функционального устройства. Получены зависимости минимальной мощности переключения от расстояния между проводами и их геометрическими параметрами в планарной и вертикальной геометрии. Продемонстрирована возможность создания многокаскадного инвертора сигнала, работающего на данном принципе.

\section{Благодарности}

Авторы выражают благодарность В.Л. Столярову, Е.Д. Ольшанскому, В.Н. Мисько, А.Г. Домантовскому, Е.В. Малиевой за изготовление исходных тонких пленок нитрида ниобия и помощь в изготовлении структур, а также Д.А. Комарову за проведение ионного облучения в процессе формирования интегрированных сопротивлений.

\section{Финансирование работы}

Работа выполнена при поддержке Национального исследовательского центра „Курчатовский институт“ (приказ от 25.06.2019 № 1359).

\section{Конфликт интересов}

Авторы заявляют, что у них нет конфликта интересов.

\section{Список литературы}

[1] D.S. Holmes, A.L. Ripple, M.A. Manheimer. IEEE Trans. Appl. Supercond. 23, 3, 1701610 (2013).

[2] F. Balestra, Y. Hayashi, T. Contre-vice-chair. The international roadmap for devices and systems. IEEE (2018). 32 p.

[3] K.K. Likharev, V.K. Semenov. IEEE Trans. Appl. Supercond. 1, 1, 3 (1991).

[4] N. Takagi. Phys. C, 484, 213 (2013).

[5] A.N. McCaughan, K.K. Berggren. Nano Lett. 14, 10, 5748 (2014).

[6] W. Chen, A.V. Rylyakov, Vijay Patel, J.E. Lukens, K.K. Likharev. IEEE Trans. Appl. Supercond. 9, 2, 3212 (1999).

[7] Technical data on IBM Power 9 chip [Electronic resource]. URL: en.wikichip.org/wiki/ibm/power/02cy296.

[8] Б.А. Гурович, К.Е. Приходько, А.Г. Домантовский, В.Л. Столяров, Д.А. Комаров, Е.А. Кулешова, Л.В. Кутузов. Патент РФ № 2674063. Бюл. № 34. (2018). 13 с.

[9] A.D. Semenov, G.N. Gol'tsman, A.A. Korneev. Phys. C 351, 4, 349 (2001).

[10] G. Goltsman, A. Korneev, V. Izbenko, K. Smirnov, P. Kouminov, B. Voronov, N. Kaurova, A. Verevkin, J. Zhang, A. Pearlman, W. Slysz, R. Sobolewski. Nucl. Instrum. Meth. Phys. Res. A 520, 1-3, 527 (2004)

[11] L. Jiang, J. Li, W. Zhang, Q.J. Yao, Z.L. Lin, S.C. Shi, Y.B. Vachtomin, S.V. Antipov, S.I. Svechnikov, B.M. Voronov, G.N. Goltsman. IEEE Trans. Appl. Supercond. 15, 2, 511 (2005).

[12] B.S. Karasik, A.V. Sergeev, D.E. Prober. IEEE Trans. Terahertz Sci. Technol. 1, 1, 97 (2011).

[13] J. Clarke. Proc. IEEE, 77, 8, 1208 (1989).

[14] Б.А. Гурович, К.Е. Приходько. УФН 179, 2, 179 (2009).

[15] Б.А. Гурович, К.Е. Приходько, Е.А. Кулешова, К.И. Маслаков, Д.А. Комаров. ЖЭТФ 143, 6, 1062 (2013).

[16] Б.А. Гурович, М.А. Тархов, К.Е. Приходько, Е.А. Кулешова, Д.А. Комаров, В.Л. Столяров, Е.Д. Ольшанский, Б.В. Гончаров, Д.А. Гончарова, Л.В. Кутузов, А.Г. Домантовский. Рос. нанотехнологии 9, 7-8, 36 (2014).

[17] М.М. Дементьева, К.Е. Приходько, Б.А. Гурович, Л.В. Кутузов, Д.А. Комаров. ФТТ 58, 11, 2104 (2016).

[18] В.В. Шмидт. Введение в физику сверхпроводников. МЦНMO, M. (2000). 397 c.

[19] W.J. Skocpol, M.R. Beasley, M. Tinkham. J. Appl. Phys. 45, 9 , 4054 (1974).

[20] Б.И. Ивлев, Н.Б. Копнин. УФН 142, 3, 435 (1984). 
[21] W.W. Webb, R.J. Warburton. Phys. Rev. Lett. 20, 9, 461 (1968).

[22] K. Harrabi, A. Mekki, S. Kunwar, J.P. Maneval. J. Appl. Phys. 123, 8, 083901 (2018).

[23] Б.А. Гурович, К.Е. Приходько, М.А. Тархов, Е.А. Кулешова, Д.А. Комаров, В.Л. Столяров, Е.Д. Ольшанский, Б.В. Гончаров, Д.А. Гончарова, Л.В. Кутузов, А.Г. Домантовский, 3.В. Лаврухина, М.М. Дементьева. Рос. нанотехнологии 10, 7-8, 21 (2015).

[24] B.A. Gurovich, K.E. Prikhodko, M.A. Tarkhov, A.G. Domantovsky, D.A. Komarov, B.V. Goncharov, E.A. Kuleshova. Micro Nanosyst. 7, 3, 172 (2015).

[25] L.M. Johnson. Proc. 2018 MIT Research and Development Conf. (2018). [Electronic resource].

URL : http: // ilp. mit. edu / images / conferences / 2018/rd / presentations / Johnson.2018.RD.pdf

Редактор Ю.Э. Китаев 